\title{
Teachers' Understanding of Menstrual Cycle in Navakholo Sub-County, Kakamega County, Kenya
}

\author{
Jedidah M. Sakwa \\ Department of Psychology \\ University of Nairobi \\ Luke Odiemo Okunya (Corresponding author) \\ Department of Psychology \\ University of Nairobi
}

Received: August 20, 2018 Accepted: October 1, 2018 Published: November 18, 2018

doi:10.5296/ijld.v8i4.13927ＵRL: https://doi.org/10.5296/ijld.v8i4.13927

\begin{abstract}
Teenage pregnancy is a major social problem in Kakamega County in Kenya that tends to have negative ramifications especially on the lives of young girls. Recent studies have documented school children lack the necessary skills to manage their sexual life due to the misconceptions they have about menstrual cycle despite having gone through Kenyan school science curriculum. This can be supported by worldwide reports that teachers can actually be one of the sources of such misconceptions in their learners. This study sought to assess teachers' understanding of menstrual cycle in Navakholo sub-county, Kakamega County, Kenya. A case study design with a mixed-method approach was used in two secondary schools in Navakholo sub-County, Kakamega County Kenya. A mixed gender sample of 20 teachers aged 24 years and above, responded to a multiple choice questionnaire targeting the menstrual cycle concept. Four focus group discussions and 4 Key Informant Interviews were conducted. Three levels of understanding emerged in the data analysis, i.e., Full Comprehensive Basic, Full Comprehensive Intermediate and Full Comprehensive Understanding. There was a statistically significant relationship be full comprehensive understanding level and ones knowledge of menstrual cycle, $\left(\chi^{2}=13.7620, p=0.003\right)$. Basic understanding was found to have no statistically significant effect on knowledge $(\mathrm{t}=-0.44, \mathrm{p}=0.661)$ at the $5 \%$ level of significance. Intermediate understanding was found to have statistically significant effect on knowledge $(\mathrm{t}=-1.89, \mathrm{p}=0.062)$ at the $10 \%$ level of significance. Full understanding had positive and statistically significant effect on knowledge $(\mathrm{t}=5.33, \mathrm{p}=0.0000)$ at the $5 \%$ level
\end{abstract}


of significance. As the understanding graduated from basic through intermediate to full comprehensive understanding, the fewer the number of respondents who achieved higher level of understanding. Full comprehensive understanding of the concept of menstrual cycle was not achieved by the majority meaning that teachers lack a high level understanding of the menstrual cycle concept.

Keyword: menstrual cycle, teachers' understanding

\section{Introduction}

Teenage motherhood is a major social challenge in Kenya. A report by Population Reference Bureau (PRB) (2015) documented that 18\% of teenage girls aged between 15 to 19 years are mothers. Besides other measures meant to stem this problem, equipping children with the scientific knowledge of menstrual cycle has been found to be an important life-skill (Motaboge, Beukes, \& Nolte, 2014). Female reproduction system is covered in grade 6 in the Kenyan school curriculum with menstrual cycle only mentioned in passing (Nyamosi et al., 2015). Similar content is also covered in grade 11 at the secondary school level under the subject of Biology but despite this teenage pregnancy remains a lot high. It could be an indication that the knowledge of human reproduction is yet to translate into strategies to manage teenage sexuality in a manner that enables them make rational choice about their sex life so as to improve their wellbeing. This begs a question "are Kenyan children being taught well when it comes to menstruation, menstrual cycle and their explicit link to their sexuality?" (Sakwa \& Odiemo, 2018).

Cultural and religious beliefs have curtailed social interaction among knowledgeable members and their less knowledge peers in the community with regard human sexuality. Consequently, teachers remain the main source of scientific knowledge regarding menstruation and menstrual cycle among students (Ramathuba, 2015). Yet a number of studies have questioned the quality of learning in Kenyan schools. A study by Uwezo (2014) on Kenyan teachers understanding of school curriculum content reported that some teachers had difficulty tackling tasks meant for grade 6 pupils. Another later study by The School Fund (2015) demonstrated that the quality of learning in Kenyan schools is still low. Three (3) out of ten (10) class three (3) children could not tackle class two (2) work while for class 8 children 8 out of 100 pupils in Class 8 could not do Class 2 work across the country. On average, only 30 out of 100 Class 3 pupils could do Class 2 work. Looking at individual subjects, on average, at least 4 out of 10 pupils in Class 3 could do Class 2 work, but only 3 out of 10 could tackle all the three subjects (The School Fund, 2015). A recently published study reported that Kenyan secondary school students lack a comprehensive understanding of menstrual cycle as per the curriculum expectations. This was largely caused by various cultural sources of this knowledge from which children get socialized about sexuality beside the school science curriculum. These sources have misconceptions about human reproduction and are rarely explicit on how it impacts strategies for managing sexuality (Sakwa \& Odiemo, 2018). Such misconceptions pose a serious challenge to learning scientific concepts among learners (Clement, Brown, \& Zietsman, 1989). It is therefore, important that as the key source of knowledge on reproduction and sexuality (Ramathuba, 2015), teachers are knowledgeable 
enough in their subject areas to adequately help a learner confront and change these misconceptions so as to equip them with strategies to manage their sexuality (Schmidt, 1995). Unfortunately, previous research has reported that teachers can sometimes be a source of misconception of science concepts as a result of their own misunderstanding of phenomena (Yates \& Marek, 2014; Lawrenz, 2010; Kwen, 2005).

With regard to the delivery of the curriculum on human reproduction, it has also been reported that most teachers felt it was not their responsibility to teach children about sexuality; neither was there approval to teach students about menstruation. They also felt ill prepared to handle this subject matter since it was never part of the school or teacher training curriculum when they were students in school or trainee teachers in college (McMahon et al., 2011). It has been reported that in an attempt to explain menstrual cycle, girls rarely address all the aspects of the process. Instead they focus one meticulous component of the process such as ova or blood or the uterus (Koff \& Rierdan, 2008; McMahon et al., 2011). A similar study by Julius (1992) teachers concurred with McMahon et al. (2011) that in as much as sex was openly discussed at school, menstruation was often covered in one brief lesson that emphasized the biological aspect without emotional or practical attachments that are important for the learner to translate human reproduction knowledge into strategies to manage sexuality (Julius, 1992).

In a similar study done by Chandra-Mouli and Patel (2017) 70-90\% of school teachers who had been trained to use various strategies especially play approaches to pass menstruation knowledge to their students found it rather easy and confident to discuss these matters with their students. However, the counterpart who had not been trained on the same found it difficult to discuss menstruation and menstrual cycle. They therefore, provided limited information concerning menstrual cycle to their students leading to limitation in the students' ability to handle their own sexuality (Chandra-Mouli \& Patel, 2017). Besides religious leaders on their part perceive menstrual cycle education a catalyst that can drive children into sexual promiscuity, with boys and teachers too embarrassed to talk about menstrual health with their own children (ibid).

It was further observed that, despite teachers being trained in human sexuality and reproduction as part of their teacher training curriculum, teachers are never convinced to teach menstrual cycle to small children due to cultural taboos regarding sex. Where they attempted to teach, they committed scientific errors about aspects of the human female body vis-a-vis sexuality (Veiga et al., 2007). The female teachers approached this matter with an assumption that the ability to cope with female sexuality challenges was inherent in all females since they themselves managed them too needed to cope (Julius, 1992). For example, students normally received necessary support from their teachers on matters pertaining to menstruation based on the teachers' past experience and their personal opinions rather than what the official curriculum dictated (African Population and Health Research Centre, 2010). The information they received mostly entailed cleanliness during menstruation and keeping away from boys rather than emphasizing the biological knowledge on menstruation and menstrual cycle at the expense of human sexuality that constitutes the social aspect of human reproduction (African Population and Health Research Centre, 2010). 


\section{Macrothink}

International Journal of Learning and Development

ISSN 2164-4063

2018, Vol. 8, No. 4

A number of teachers do not know what menstrual health good practices are and therefore cannot advice girls or answer girls' questions about what activities are safe or unsafe during menstruation and also menstrual cycle covered by existing curriculum and teaching materials is not adequate (Ministry of Education, 2014, 2016). A study done by Raya et al. (2013) in Indonesia teachers confirmed that teachers lacked understanding of biology of the menstrual cycle and were not able to address all the questions of adolescent girls. The respondents did not have the menstrual knowledge to assertively counsel on menstrual cycle. Raya et al. (2013) reported that some teachers assumed that girls already had the knowledge on menstrual cycle and so did not need to be taught. The standard curriculum or teaching materials did not include menstruation and menstrual cycle and therefore was not prioritized which is detrimental to growing up students because when they do not understand the menstrual cycle they cannot control teenage pregnancy by use of safe day with the menstrual cycle (Raya et al., 2013).

Women rarely share information about menstruation with men and boys. Most men therefore, do not know about the normal physiology of menstruation, such as the menstrual cycle yet this is what is supposed to enable the boys develop knowledge of human sexuality. Only $22 \%$ of men knew the phase of menstrual cycle in which a woman is fertile enough to conceive. This means that men are not likely to manage their sexuality in a way that compliments women's effort to prevent unwanted pregnancies (Mahon et al., 2015). While United Nations Educational, Scientific and Cultural Organization (UNESCO) (2014) agreed with Mahon et al. (2015), they emphasized that male teachers were not adequately trained to attend to girls' needs. The UNESCO (2014) report recommended that male teachers should be knowledgeable enough regarding menstrual cycle and menstrual health management. This will enable girls improve their management of their sexual life so as to maintain female students in school to completion and thus good quality life in future.

It is necessary for training schools to give more consideration to the training of school teachers in sexuality and human reproduction (Veiga et al., 2007). With the cultural sources of alternative conceptions of phenomena still in place (Sakwa \& Odiemo, 2018), it was necessary to establish whether Kenyan teachers are knowledgeable enough to counteract the influence of alternative conceptions on learners understanding of menstrual cycle. This study therefore, assessed the teachers understanding of menstrual cycle to ascertain the information teachers are passing to young people regarding menstruation and menstrual cycle towards management of teenage sexuality.

\section{Method}

This study employed case study design. A structured multiple-choice questionnaire targeting the menstrual cycle knowledge was administered to male and female teachers for quantitative data. Qualitative data was collected via Focus Group Discussions (FGDs) and Key Informant Interviews (KIIs) among the male and female teachers and school principals to fill gaps in the results from the quantitative data. 


\subsection{Target Population}

The target population of this study was teachers aged twenty four (24) years and above from two public mixed secondary schools in Navakholo Sub County Kakamega County. There were a total of 40 teachers of both genders in the two schools. Secondary School A had a total of 24 teachers where 14 were females and 10 were males. Secondary School B had a total of 16 teachers of whom 10 were females and 6 were males.

\subsection{Sampling Procedure}

Purposeful random sampling technique was used. Ten teachers were selected in which five male and five female teachers from each secondary schools were sampled to compete the multiple choice questionnaire. Four members of equal gender were purposively sampled to participate in Focus Group Discussions (FGDs). Key Informants Interviews (KII) participants were also purposively sampled. In this case, the principals of the respective schools and their deputies were selected.

\subsection{Sample Size}

A total of 21 respondents completed the self-administered multiple choice questionnaire. Of these 11 were females and the other were males including the principals and deputy principals of the two sampled schools. Four participants were aged between 26 and 30; eight between 30-40, six ranged between 41-50 and two were above 50 years of age. In terms of settlement, 16 resided in rural setting with 5 living urban areas. As for education levels, 17 participants held bachelor of education degree, two of them had a master of education qualification with the remaining two holding a diploma and a certificate in education respectively. In terms of income, three participants earned between $\$ 100-200$ per month. Another three earned between \$201-300 per month, seven earned between \$301-400, three earned \$401-500 while the remaining five participants earned between \$501-1000 per month. As for the teaching experience, eight participants had worked for between 1-5 years, five had 6-10 years of experience and seven of them had worked for at least 16 years with the remaining participant having worked for between 11-15 years. In addition 4 Focus Group Discussions comprising 4 members purposively drawn from both genders from each school were selected. A sample of 2 school principals and 2 deputy school principals took part in the Key Informant Interview.

\subsection{Instruments}

Three research instruments were used to collect data. Key Informant Interview guide was used to conduct Key Informant Interview. Focus group discussion guide was applied in the Focus Group Discussions. Both instruments were semi-structured in format. A structured multiple-choice questionnaire was administered for quantitative data on the understanding of menstrual cycle among teachers. Section A of the structured multiple-choice questionnaires was used to acquire information on the background of the participants and section B included the information associated to the objectives of the study. The questionnaire was developed on the basis of Kenyan school science curriculum regarding human reproduction. 


\section{I Macrothink}

\subsubsection{A Structured Multiple-Choice Questionnaire}

Multiple choice questionnaires are one of the objective tools whose items can easily be scored objectively and allows proper sampling of the content. The format of the test had more than two alternatives (Holder \& Mills, 2001). For this study, the test items had four alternatives in which the respondents were required to choose from the four alternatives one that is correct or best describe the given scenario. Among the alternative there was one correct answer and three wrong ones which are always referred to as distracters.

This tool consisted of 50 multiple choice questions divided into 5 sections each 10 points. The first section was on definition of menstrual circle which comprised of 5 key elements in order to score the ten points. The second section was on labeling of the diagram of female reproduction system and to identify the parts of the female reproductive system together with their functions. The third section was on identification of menstrual cycle phases and at what period of the month each phase occurs while the fourth was on the hormones that control the events of menstrual cycle. Naming of the hormones and the stage at which each one of them is released during the cycle. The fifth section comprised of questions on start and cessation of menstruation. Also relating the phases and the hormones that control menstrual cycle and demonstrating knowledge on how conception occurs.

\subsubsection{Key Informant Interview Guide or Schedule}

The interview schedule was developed by the researcher which was guided by the key elements in the concept of the menstrual cycle as described by in the multiple choice tool. It was filled by the research assistants while conducting key informant interviews with the deputy and head teachers of the selected schools.

\subsubsection{Focus Group Discussion Guide}

Short structured questionnaire consisting of short and simple questions was developed to guide the focus group discussions of various groups i.e. Male and female teachers. Again the question involved the key elements of menstrual cycle and the cultural and religious question to capture the respondents believe system.

\subsection{Data Collection Procedure}

In order to observe cultural sensitivities regarding menstrual cycle, 2 female research assistants conducted questionnaires, Key Informant Interviews and FGDs with female teachers while 2 male research assistants conducted the FGDs with male teachers. Note-taking took place throughout discussions by trained note-takers who were seated within circle. A male note-taker sat in the group of male discussants and female one for the female discussants. Note-taking provided a means to record valuable, unspoken and aspects of the discussions.

\section{Data Analysis}

All FGDs and KII was manually transcribed into electronic format and then qualitative data was analyzed thematically by the researcher and supported by one research assistant. 
Qualitative data was coded under the following themes: "Definition of menstrual cycle", "Sources of information", "Quality of the information regarding menstrual cycle" and "Attitudes towards menstrual cycle".

With regard to the quantitative data, binary scores were used to assess scientific understanding of menstrual cycle with (1) for a correct response and a zero (0) for wrong response. The researcher came up with three categories of understanding premised on the fact that individual differences such as level of education, cultural background and gender among other demographic factors can determine the level of understanding one has about a phenomenon (Keraro, 2009). The categories were Basic Understanding, Intermediate Understanding and Full Comprehensive Understanding. The categories were derived from previous studies. Basic understanding was considered to be the knowledge acquired at Primary school level in which science subject is taught and the science of the female reproductive system was covered in which menstrual cycle was only mention in passing as from class six (Nyamosi et al., 2015; Ministry of Education, 2014). Intermediate understanding was considered to be the secondary school biology that covers menstrual cycle in Biology in grade 11 according to Ministry of Education (2016). Full comprehensive understanding comprises university and teachers' training college level of scientific knowledge expected of practicing teachers (Chandra-Mouli \& Patel, 2017).

\subsection{Basic Understanding}

This category of understanding was the most basic expected of primary school pupil. It involved knowledge on the female reproduction system, parts of female reproductive system and some knowledge on definition of menstrual cycle (Nyamosi et al., 2015, KBL, 2014). The major components are correct identification of female reproductive system (1), its parts as Vagina (1), cervix (1), myometrium (1), uterus (1), fallopian tubes (1), fimbriae (1), ovary (1) and endometrium (1). Finally in the basic comprehension the respondents will be required to know how the start of menstruation is referred to as menarche (1). The respondent was also supposed to define what menstrual cycle is by outlining its major components namely, the monthly cycle (1), changes in the ovaries (1), changes in the lining of the uterus (1), the shedding of the endometrium (1) and the start of menstruation is referred to as menarche (1). For each correct response, a participant was assigned (1) as indicated in the parenthesis besides each element of Basic Understanding. In total, complete Basic Understanding required the knowledge of 14 entities. It comprised fourteen (14) terms in whose scores were grouped in four for ease of further categorizing the respondents in various sub-categories of the Basic Understanding. A total score of zero (" 0 ") meant "No Understanding"; if a respondent attained 1-5 terms right it corresponded to "Basic Simple Understanding" of the Basic Understanding. A score of 6-10 terms corresponded to "Intermediate Basic Understanding" and 11-14 represented "Basic Comprehensive Understanding".

\subsection{Intermediate Understanding}

In this category, a respondent was required to score the elements of Basic Understanding as well as identify the number of phases involved in the menstrual cycle (1) and the average length of menstrual cycle (1). The respondent was further expected to identify the actual 
phases namely, menstruation (1), follicular (1), ovulation (1) and luteal (1). A complete Intermediate Understanding meant that a respondent had knowledge of 21 aspects of menstrual cycle. In this case, a score of at least 16 elements of constituted Intermediate Understanding. It comprised twenty (21) terms in the above mentioned areas of the menstrual cycle concept. The scores were divided into four sub-categories where 1-5 terms right represented "No Understanding", 6-10 terms right represented "Intermediate Basic Understanding" of this category, a score of 11-15 corresponded to "Intermediate Understanding" with 16-21 representing "Comprehensive Intermediate Understanding”.

\subsection{Full Comprehensive Understanding}

Full Comprehensive Understanding means that the respondents understood fully the scientific description of menstrual cycle, phases and the relationship with the hormones controlling female reproductive system. In this category therefore, the respondent was required to demonstrate Intermediate Understanding coupled with the knowledge of the hormones that control menstrual cycle events namely, estrogen (1), progesterone (1), luteinizing (1) and follicle stimulating (1). It comprised of twenty four (24) aspects of the menstrual cycle concept. The scores were further sub categorized into four sub-categories whereby a score of 1-6 represented "No Understanding", 7-12 meant "Full Comprehensive Basic Understanding", 13-18 meant "Full Comprehensive Intermediate Understanding" with a score of 19-24 standing for "Full Comprehensive Understanding."

Finally, quantitative data were entered into version 20 of Statistical Package for Social Sciences (SPSS). The researcher used descriptive statistics distribution frequencies, central tendencies and dispersions were calculated. Spearman's correlation coefficient was used to establish the relationship between the several confounding variables discussed like age, gender, religion, level of education, socio-economic status and work experience with their understanding of menstrual cycle. A repeated measures ANOVA was applied to determine the significance of various demographic factors in the teachers' level of conception of menstrual cycle.

\section{Ethical consideration}

The researcher obtained permission to conduct the study from the University of Nairobi department of psychology through an authorization letter. A research permit from the National Council of Science and Technology and Innovation was also requested by the researcher. Thereafter the researcher visited the two schools to request the schools' boards of management and head teachers to be allowed to carry out the study. The researcher obtained an informed consent from the participants and adhered to all the mandatory research ethics during the study.

\section{Results}

The reported findings addressed the following: (i) teachers' sources of information about menstrual cycle (ii) teachers understanding of the menstrual cycle concept and (iii) factors influencing teachers understanding of menstrual cycle. 


\section{Macrothink}

\subsection{Teachers' Sources of Information Regarding Menstrual Cycle}

Due to difference in experience regarding menstrual cycle, it was expected that there would be gender differences about where women and men got information. All the female respondents had already experienced menstruation which accounted to $50 \%$ of all respondents in this study. On assessing whether they had received information prior starting their period seven female teachers (41.6\%) affirmed they had while $4(8.4 \%)$ said they had not. But while evaluating if they had adequately been prepared for the first period only 4 participants (19\%) said they had been prepared while seven of them (33.3) had not, meaning that most of the people are not always adequately prepared for menarche. Most of them said they encounter menstruation through direct experience when they began menstruating. Of the female respondents $4(23.8 \%)$ had started their period between 14 and 15 years. Another 2 $(19 \%)$ experienced it when they were between 11 to 13 years whereas only $1(4.8 \%)$ started menstruating when above 15 years.

During the focus group discussion especially the male focus and the male Key Informants the researcher investigated if at any age of their life someone had introduced to them the topic of menstrual cycle and menstruation before the school such as their parents. Most of them had the following sentiments:

Key informant W: That is a female thing. Meaning males were not meant to know or understand menstruation and menstrual cycle.

FGD A: It was and is still a taboo for a man to get involved with such. Implying his religious and cultural beliefs and practices did not allow men to know anything.

FGD E: No not at all - silence.

As for where they got information about menarche, table 1 below shows that the most common source of information for teachers was friends and peer in which 7 (33.3\%) followed by school and family members especially sisters and aunts at 6 (28.6) each and finally the least source of information for teachers was health worker at $2(9.5 \%)$. The results coincided with the focus group findings in which they were asked to name their main sources of information regarding menstrual cycle. Most of them mentioned friends and peers to have been their main sources of information as demonstrated below:

Chorus of many: Friends and peers but others such as:

FGD female A: Pretended to be sick and when I was taken to the clinic I asked the nurse who explained to me. 


\section{Macrothink}

Table 1. Teachers' sources of information on menstrual cycle

\begin{tabular}{lll}
\hline Source of information & Frequency (n) & Percent (\%) \\
\hline School(Teacher) & 6 & 28.6 \\
Church(Pastor or Reverend) & - & - \\
Handbills and leaflets & - & - \\
Banners and posters & - & - \\
Family members(e.g. parents, sisters, aunts) & 6 & 28.6 \\
Friend and peers & 7 & 33.3 \\
Movies, cinema and film & - & - \\
Health workers (e.g. doctors, nurses etc.) & 2 & 9.5 \\
Television & - & - \\
\hline
\end{tabular}

\subsection{Teachers' Understanding of Menstrual Cycle}

The study sought to establish teachers' understanding of menstrual cycle. Three levels of understanding were identified in a graduating manner. That is, the same participants were scored across all categories to establish how well the teachers understood the concept.

\subsection{Teachers'Basic Understanding of Menstrual Cycle}

Most of the teachers $18(85.7 \%)$ had Basic Intermediate Understanding, followed $2(9.5 \%)$ with Basic Simple Understanding, 1 (4.8\%) Basic Comprehensive Understanding with none of the teachers having No Understanding of the female reproductive system and definition of menstrual cycle. In addition the teachers' responses during focus group discussion when they were asked if teachers had enough information about menstrual cycle demonstrated their limited understanding of menstrual cycle as illustrated below:

Teacher C: Not quite, unless those who teach biology.

Another Teacher E: Not quite I lack information on various phases, hormones and the safe period when fertilization cannot occur.

\subsection{Teacher's Intermediate Understanding of Menstrual Cycle}

In this category, $10(47.6 \%)$ of the teachers demonstrated Intermediate Basic Understanding and Intermediate Understanding. Only one teacher (4.8\%) had No Understanding and none of the teachers had Intermediate Comprehensive Understanding.

\subsection{Teachers' Full Comprehensive Understanding of Menstrual Cycle}




\section{Macrothink}

Over half 11 (52.4\%) of the respondents achieved Full Comprehensive Basic Understanding in this category, followed by 8 (38.1\%) with Full Comprehensive Intermediate Understanding followed by $1(4.8 \%)$ with Full Comprehensive Understanding. Only 1 (4.8\%) teacher had no understanding at all of Full Comprehensive Understanding level of menstrual cycle.

Table 2. The regressions results on the effect of the basic, intermediate, and full understanding on knowledge

\begin{tabular}{|c|c|c|c|c|c|}
\hline Knowledge & $\beta$ & Robust SE $\beta$ & t-statistic & P-Value & $95 \%$ CI \\
\hline Constant & .00987 & .46323 & 0.02 & 0.983 & {$[.9123, .9321]$} \\
\hline $\begin{array}{l}\text { Basic } \\
\text { Understanding }\end{array}$ & .02757 & .06257 & -0.44 & 0.661 & {$[.1521,0970]$} \\
\hline $\begin{array}{l}\text { Intermediate } \\
\text { Understanding }\end{array}$ & -.44038 & .23303 & $-1.89 * *$ & 0.062 & {$[.9043, .0235]$} \\
\hline $\begin{array}{l}\text { Full } \\
\text { understanding }\end{array}$ & .10510 & .01974 & $5.33^{*}$ & 0.000 & {$[.0658, .1444]$} \\
\hline$R^{2}$ & & & & & \\
\hline Root MSE & & & & & \\
\hline No. of observation & 8 & & & & \\
\hline
\end{tabular}

Note. $* *$ and $*$ mean significant at $10 \%$ level of significance respectively

Table 2 above presents the regression results on the effect of the Basic, Intermediate and Full Understanding on the knowledge of menstrual cycle. The fitted model was a good fit ( $\mathrm{F}=9.58$, $\mathrm{p}=0.0000$ ) meaning the model did not suffer from miss-specification. The $\mathrm{R}^{2}$ for the model was 0.1828 meaning the proportion of variation in knowledge explained by the regressors was $18.28 \%$. The low $\mathrm{R}^{2}$ is common for survey data like the one used in this analysis. Basically an $\mathrm{R}^{2}$ of $15 \%$ for survey or cross-sectional datasets is deemed satisfactory. The $\mathrm{R}^{2}$ for this study therefore was deemed satisfactorily big enough.

Basic Understanding was found to have no statistically significant effect on knowledge $(\mathrm{t}=-0.44, \mathrm{p}=0.661)$ at the $5 \%$ level of significance. Specifically, the Basic Understanding was found to have a negative effect on knowledge of $\beta=-.02757$ units, on average, holding the effect of the Intermediate and Full Understanding constant.

Intermediate Understanding was found to have statistically significant effect on knowledge $(\mathrm{t}=-1.89, \mathrm{p}=0.062)$ at the $10 \%$ level of significance. Specifically, the intermediate level of understanding was found to have negative effect on knowledge of $\beta=-.44038$, on average, 
holding the effect of the basic and the full levels of understanding constant.

Full Understanding had positive and statistically significant effect on knowledge $(\mathrm{t}=5.33$, $p=0.0000$ ) at the $5 \%$ level of significance. It had a positive effect of $\beta=.10510$, on average, holding the effect of the basic and intermediate levels of understanding constant.

It shows that only the full level of understanding that was found to have a positive and statistically significant effect on knowledge. It means respondents with full understanding have the best knowledge.

Table 3. Three-way Chi-Square on understanding and knowledge

\begin{tabular}{lclc}
\hline Knowledge & DF & Chi-Square statistic & P-value \\
\hline Asic understanding & 81 & 12.7593 & 0.917 \\
Intermediate understanding & 81 & 2.0427 & 0.564 \\
Full understanding & 81 & $13.7620^{*}$ & 0.003 \\
\hline
\end{tabular}

Note. $*$ means significant at the $5 \%$ level of significance

Table 3 presents the three-way Chi-square on the relationship between understanding and knowledge. Three sets of hypotheses were tested. The first set of hypothesis that was tested stated that there is no statistically significant relationship between basic level of understanding and knowledge. This hypothesis was not rejected at the 5\% level of significance $\left(\chi^{2}=12.7593, p=0.917\right)$ meaning the basic level of understanding does not have significant influence on knowledge.

The second set of hypothesis stated that there is no statistically significant relationship between the intermediate level of understanding and knowledge. The hypothesis was not rejected at the $5 \%$ level of significance $\left(\chi^{2}=2.0427, p=0.564\right)$ meaning the intermediate level of understanding does not have significant influence on knowledge.

The third hypothesis stated that there is no statistically significant relationship between the full level of understanding and knowledge. The hypothesis was rejected at the $5 \%$ level of significance $\left(\chi^{2}=13.7620, p=0.003\right)$ meaning the full level of understanding has a significant influence on knowledge.

\subsection{Factors Influencing Teachers' Overall Understanding of Menstrual Cycle}

There was association between understanding of menstrual cycle and the age and gender of the teacher. Table 4 below presents three-way Chi-square on the relationship between the three levels of understanding and age. Three sets of hypotheses were tested. The first hypothesis stated that there is no statistically significant relationship between basic understanding and age. The second set of hypothesis stated that there is no statistically 


\section{Macrothink}

International Journal of Learning and Development

ISSN 2164-4063

2018, Vol. 8, No. 4

significant relationship between intermediate level of understanding and age. The third hypothesis stated that there is no statistically significant relationship between the full level of understanding and age. The three sets of hypotheses were not rejected $\left(\chi^{2}=18.4561, p=0.187\right)$, $\left(\chi^{2}=1.6581, p=0.436\right)$, and $\left(\chi^{2}=1.9524, p=0.377\right)$ at the $5 \%$ level of significance. The implication was that age does not have a statistically significant influence on understanding.

Table 4. Three-way Chi-square between understanding of menstrual cycle and age

\begin{tabular}{lcll}
\hline Age & DF & Chi-Square statistic & P-value \\
\hline Basic understanding & 81 & 18.4561 & 0.187 \\
Intermediate understanding & 81 & 1.6581 & 0.436 \\
Full understanding & 81 & 1.9524 & 0.377 \\
\hline
\end{tabular}

Table 5 below presents results of the three-way Chi-square on the relationship between gender and understanding. Three sets of hypotheses were tested. The first set of hypothesis stated that there is no statistically significant relationship between gender and the basic level of understanding. The second hypothesis stated that there is no statistically significant relationship between gender and the intermediate level of understanding. The third hypothesis stated that there is no statistically significant relationship between gender and the full level of understanding. The three sets of hypotheses were rejected $\left(\chi^{2}=15.6511, p=0.029\right),\left(\chi^{2}=6.8457\right.$, $\mathrm{p}=0.009)$, and $\left(\chi^{2}=12.6202, \mathrm{p}=0.000\right)$ at the $5 \%$ level of significance respectively. The implication is that gender has statistically significant influence on understanding.

Table 4. Three-way Chi-square between understanding of menstrual cycle and gender

\begin{tabular}{lcll}
\hline Gender & DF & Chi-Square statistic & P-value \\
\hline Basic understanding & 81 & $15.6511^{*}$ & 0.029 \\
Intermediate understanding & 81 & $6.8457^{*}$ & 0.009 \\
Full understanding & 81 & $12.6202^{*}$ & 0.000 \\
\hline
\end{tabular}

Note. * means significant at the $5 \%$ level of significance

Generally, gender was found to have a statistically significant influence on understanding while age had no statistically significant influence on understanding. 


\section{Discussion}

The most common source of information for teachers was friends and peer in which $7(33.3 \%)$ followed by school and family members especially sisters and aunts at 6(28.6) each and finally the least source of information for teachers was health worker at 2(9.5\%). APHRC (2010) found out that girls in school felt teachers were supportive by informing them but more often informal, based on the teachers general knowledge as well as their personal opinion rather than what the official curriculum dictates. Also, the information provided in most cases was aimed to caution girls as to maintaining hygiene (African Population and Health Research Centre, 2010).

The teachers' understanding was evaluated by use of a multiple choice questionnaire and there after classified in three categories namely Basic, Intermediate and Comprehensive Understanding based on the important terms in the concept of menstrual cycle. Menstrual cycle involved twenty four terms in which basic understanding was fourteen terms, intermediate understanding twenty terms and full comprehensive had twenty four terms. The terms included terms of the previous level of understanding as the evaluation progressed towards full comprehensive understanding in a graduating manner. According to the study findings $18(85.7 \%)$ teachers out of $21(100 \%)$ had Basic intermediate understanding followed by $11(52.4 \%)$ teaches with full comprehensive basic understanding due to overlap of terms that were involved in the two level of understanding. 10(47.6\%) teachers achieved intermediate basic understanding and intermediate understanding respectively with only 1(4.8) teacher achieving full comprehensive understanding. There was a statistically significant relationship be full comprehensive understanding level and ones knowledge of menstrual cycle, $\left(\chi^{2}=13.7620, p=0.003\right)$. Basic understanding was found to have no statistically significant effect on knowledge $(\mathrm{t}=-0.44, \mathrm{p}=0.661)$ at the $5 \%$ level of significance. Intermediate understanding was found to have statistically significant effect on knowledge $(\mathrm{t}=-1.89, \mathrm{p}=0.062)$ at the $10 \%$ level of significance. Full understanding had positive and statistically significant effect on knowledge $(\mathrm{t}=5.33, \mathrm{p}=0.0000)$ at the $5 \%$ level of significance.

These findings on most teachers lacking full comprehensive understanding concurred with McMahon et al. (2011) who conducted a study in rural Kenya and reported that teachers felt it was not their responsibility and was beyond their teaching approval to teach students about menstrual cycle. They had not been trained on menstruation in school as students or as teachers in training and therefore were not well prepared to teach menstrual cycle (McMahon et al., 2011). In another comparative study done by Veiga et al. (2007) it was reported that even though it was a requirement for teachers to teach about sexuality in schools, there was no clearly strategy for achieving this goal because teacher training curriculum does not offer this kind of knowledge to teachers. Also about $85 \%$ of the respondents confirmed that they were not confident enough to teach sexuality and human reproduction to teenagers in a classroom setting (Veiga et al., 2007). Julius (1992) concurred with Veiga et al. (2007) that numerous teachers said that while sex was openly discussed at school, menstruation was often covered in one brief lesson that emphasized the biological aspect, rather than its emotional or practical consequences in life. 
Mahon et al. (2015) in their study observed that only $22 \%$ of men knew the phase of menstrual cycle in which a woman is fertile enough to conceive. While UNESCO (2014) agreed with Mahon et al. (2015) emphasized that male teachers were not adequately trained to attend to girls' needs and that male teachers did not allow girls to wash rooms during class time and misunderstood the girls' failure to participate in class during their menses. In a similar study done by Chandra-Mouli and Patel (2017) they recorded that $70-90 \%$ of school teachers who had been trained to use various strategies especially play approaches to pass menstruation knowledge to their students found it rather easy and confident to discuss these matters with their students. But he agrees with the findings that teachers who had not been trained in teaching menstrual cycle found it difficult to discuss the same hence they provided limited information concerning menstrual cycle to their students (Chandra-Mouli \& Patel, 2017). Chandra-Mouli and Patel (2017) concluded knowledge gap and misconception among young people could be attributed to the adults around them especially their teachers and parents since they also lacked proper information.

While (African Population and Health Research Centre, 2010) concurred with (Chandra-Mouli \& Patel, 2017) affirmed that the students received necessary support from their teachers on matters pertaining to menstruation which the teachers based on their past experience and their personal opinions rather than what the official curriculum dictated. In the foregoing study respondents' gender was the only factor among teachers' that influenced their understanding of menstrual cycle. Gender was significant at all the three levels of understanding, Basic understanding $\left(\chi^{2}=15.6511, \mathrm{p}=0.029\right)$, Intermediate understanding $\left(\chi^{2}=6.8457, \mathrm{p}=0.009\right)$, and Full understanding $\left(\chi^{2}=12.6202, \mathrm{p}=0.000\right)$. This observation was expected as literature had shown that female teachers tended to be more knowledge about menstrual cycle than male teachers (cf. Chandra-Mouli \& Patel, 2017).

\section{Conclusion}

The findings of the study indicated that most teachers' had not acquired a "Full Comprehensive Understanding" of menstrual cycle as expected of a qualified science teacher. It is important to note that the gender of a teacher influence their level of understanding significantly. As to whether this lack of full understanding of this concept impacted on learners' understanding in class is an area of interest for future research in this area. Further research can also seek to understand whether gender-focused sensitization of teachers about this concept can improve their progressive understanding.

\section{References}

African Population and Health Research Centre (APHRC) (2010). Experiences and problems with menstruation among poor women and schoolgirls in Nairobi, Kenya. An Evidence-Based Policy Brief. Policy Brief No.20. Retrieved from http://www.communityledtotalsanitation.org/sites/communityledtotalsanitation.org/files/Polic yBrief_Mooncups_Kenya.pdf

Bruner, J. (1966). Toward a Theory of Instruction. Cambridge, MA: Harvard University Press. 
Chandra-Mouli, V., \& Patel, S. V. (2017). Mapping the knowledge and understanding of menarche, menstrual hygiene and menstrual health among adolescent girls in low and middle income countries. Reproductive Health, 14(30), 1-16. https://doi.org/10.1186/s12978-017-0293-6

Clement, J., Brown, D. E., \& Zietsman, A. (1989). Not all preconceptions are misconceptions: finding' anchoring conceptions' for grounding instruction on students' intuitions. International Journal of Science Education, 11(5), 554-565. https://doi.org/10.1080/0950069890110507

Holder, W. W., \& Mills, C. N. (2001). Pencils down, computer up: The new CPA exam. Journal of Accountancy, 191(3), 57-60.

Julius, C. (Thursday 15 October 1992) Education: A subject that isn't only for the girls: Menstruation affects half of all pupils, but most schools ignore it. It is time to tackle widespread ignorance. The Independent. Retrieved from https://www.independent.co.uk/news/education/education-news/education-a-subject-that-isntonly-for-the-girls-menstruation-affects-half-of-all-pupils-but-most-1557423.html

Keraro, F. N. (2009). Cultural influences on the learning of science: An African perspective. In Jonathan, E. Larson (ed). Educational Psychology: Cognition and Learning, Individual Differences and Motivation. New York: Nova Science Publishers

Kwen, H. B. (2005). Teachers' Misconceptions of Biological Science Concepts as Revealed in Science Examination Papers. Paper presented in AARE 2005 International Education Research Conference, Paramatta

Lawrenz, F. (2010). Misconceptions of Physical Science Concepts among Elementary School Teachers. School science and mathematics, 86(8), 654-66. https://doi.org/10.1111/j.1949-8594.1986.tb11669.x

Mahon, T., Tripathy, A., \& Singh, N. (2015) Putting the men into menstruation: The role of men and boys in community menstrual hygiene management. Retrieved from www.practicalactionpublishing.org. https://doi.org/10.3362/1756-3488.2015.002

Mataboge, M. L. S., Beukes, S., \& Nolte, A. G. W. (2014). Low functional health literacy, misconceptions and risks regarding prevention of unintended pregnancy, STIs, HIV and AIDS. African Journal for Physical, Health Education, Recreation and Dance, 1(Supplement 1), 127-139.

McMahon, S. A., Winch, P. J., Caruso, B. A., Obure, A. F., Ogutu, E. A., Ochari, I. A., \& Rheingans, R. D. (2011). The girl with her period is the one to hang her head' Reflections on menstrual management among schoolgirls in rural Kenya. BMC International Health and Human Rights, 11(7), 2-10. https://doi.org/10.1186/1472-698X-11-7

Ministry of Education (2016). Secondary biology new syllabus form three student book. Nairobi, Kenya: Kenya Literature Bureau

Ministry of Education (2014). Primary Science Pupils' book for standard six. $4^{\text {th }}$ edition. 
Nairobi, Kenya: Kenya Literature Bureau

Nyamosi, C., Masika, D., \& Kamoce, D. (2015).KCPE Mirror Science. Nairobi: Spotlight Publishers (EA) limited. Retrieved from http://www.spotlightpublishers.co.ke

Population Reference Bureau (PRB) (2015).Fact Sheet: Adolescent Sexual and Reproductive Health in Kenya. Retrieved from http://www.prb.org

Ramathuba, D. U. (2015). Menstrual knowledge and practices of female adolescents in Vhembe District, Limpopo Province, South Africa. Curationis, 38(1), 1-6. https://doi.org/10.4102/curationis.v38i1.1551

Raya, J., Depok, M., \& Yogyakarta, S, (2013).Menstrual hygiene management in Indonesia: Understanding practices, determinants and impacts among adolescent school girls.

Sakwa, J. M., \& Odiemo, L. (2018) Assessment of Students' Understanding of menstrual Cycle in Navakholo Sub County, Kakamega County Kenya (2018) International Journal of Learning and Development, 8(3), 42-56. https://doi.org/10.5296/ijld.v8i3.13418

The School Fund (2015). Dynamics of Education in Kenya: From School Access to Equity and Quality. Retrieved from https://theschoolfund.files.wordpress.com/2017/02/kenya-education11-9-15.pdf

Toubale, L. K. (2013). Menstrual Hygiene in Schools in 2 countries of Francophone West Africa Burkina Faso and Niger Case Studies. $2^{\text {nd }}$ MHM Virtual Conference, $21^{\text {st }}$ November, 2013. Retrieved from https://www.unicef.org/wash/schools/files/10_UNICEF_Laura_PPT_(Final).pdf

United Nations Educational, Scientific and Cultural Organization (UNESCO) (2014). Puberty Education and Menstrual Hygiene Management. Good Policy and Practice in Health Education Booklet 9. Paris: United Nations Educational, Scientific and Cultural Organization. Retrieved from http://unesdoc.unesco.org/images/0022/002267/226792e.pdf

Uwezo (2016): Are Our Children Learning? Uwezo Kenya Sixth Learning Assessment Report. Nairobi: Twaweza East Africa. Retrieved from http://www.uwezo.net/wp-content/uploads/2016/12/UwezoKenya2015ALAReport-FINAL-E $\mathrm{N}$-web.pdf

Veiga, L., Teixeira, F., Martins, I., \& Silvestre, A. M. (2007) Sexuality and human reproduction: a study of scientific knowledge, behaviors and beliefs of Portuguese future elementary school teachers. Sexuality, Society and Learning, 6(1), 17-29. https://doi.org/10.1080/14681810500508915

Yates, T. B., \& Marek, E. (2014). Teachers teaching misconceptions: a study of factors contributing to high school biology students' acquisition of biological evolution-related misconceptions. Evolution Education and Outreach $7(1)$, https://doi.org/10.1186/s12052-014-0007-2 


\section{Macrothink}

International Journal of Learning and Development

ISSN 2164-4063

\section{Copyright Disclaimer}

Copyright for this article is retained by the author(s), with first publication rights granted to the journal.

This is an open-access article distributed under the terms and conditions of the Creative Commons Attribution license (http://creativecommons.org/licenses/by/4.0/). 